\section{Anterior mediastinal mass in a young man}

John $M$ Travaline, Gerard J Criner, Pen-Ming L Ming, Friedrich Kueppers

\begin{abstract}
The case is presented of a patient in whom the diagnosis of Klinefelter's syndrome was made only after a mediastinal teratoma was discovered. Chest physicians should be aware of this association since they are often the first to evaluate patients with mediastinal masses.
\end{abstract}

(Thorax 1994;49:283-284)

\section{Case report}

A 26 year old man was referred for evaluation of a non-productive cough, sinus congestion, and right anterior chest pain. The patient's medical history was unremarkable except for a smoking history of 30 pack years and asthma since childhood. He denied constitutional symptoms. A chest radiograph (fig 1 ) indicated the presence of a large anterior mediastinal mass.

Physical examination revealed a tall, thin Caucasian man with normal vital signs. On examination of the head and neck there were no masses or lymphadenopathy. His chest was clear to auscultation, and bilateral gynaecomastia was noted. Abdominal examination showed no hepatosplenomegaly or masses. His testes were smaller than normal.

Computed tomography of the chest, head,

Division of

Pulmonary and

Critical Care

Medicine

J M Travaline

G J Criner

F Kueppers

Department of Pathology

P-M L Ming

Temple University School of Medicine, Philadelphia,

Pennsylvania 19140,

USA

Reprint requests to: Dr J M Travaline.

Received 12 January 1993 Returned to authors 3 March 1993

Revised version received 6 April 1993

Accepted for publication

13 April 1993

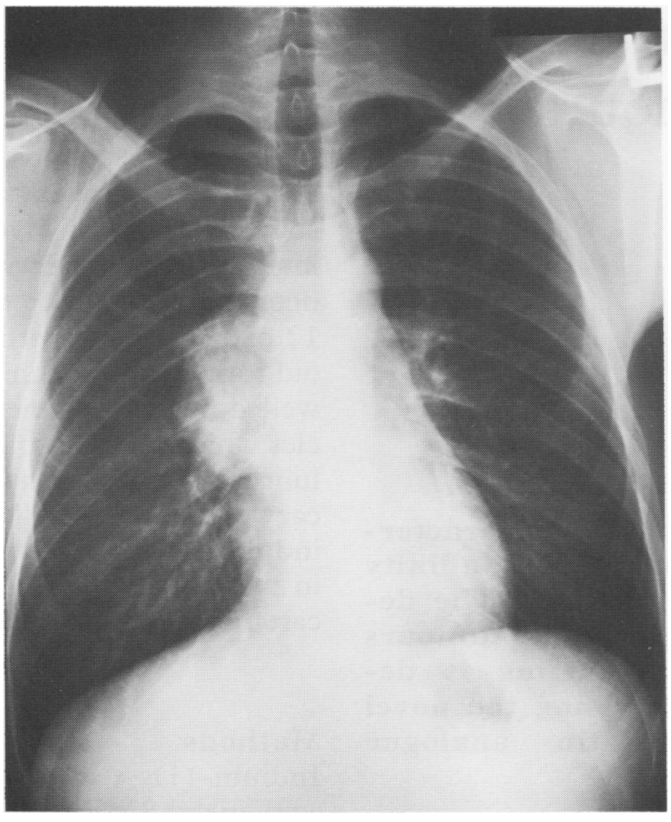

Figure 1 Posteroanterior radiographic view of the patient's chest showing the mediastinal mass. and pelvis showed a large anterior mediastinal mass containing calcium and bilateral gynaecomastia, maxillary sinusitis, and atrophic testes, respectively.

Laboratory tests revealed a normal level of $\beta$-human chorionic gonadotropin and an elevated $\alpha$-fetoprotein level of $173.7 \mathrm{ng} / \mathrm{ml}$ (normal $<9 \mathrm{ng} / \mathrm{ml}$ ). All other laboratory values were normal.

The patient underwent an exploratory median sternotomy and a well encapsulated mass was found adherent to the innominate vein, pericardium, pleura, and right phrenic nerve. The mass was successfully removed in its entirety.

The tumour was grossly heterogeneous in texture and measured $9 \times 8 \times 4.5 \mathrm{~cm}$. Examination of the cross section revealed several cysts filled with mucoid material and multiple strands of hair. Histological examination of the tumour (fig 2) showed elements of both mature ectodermal and mesodermal germ cell lines consistent with the histological diagnosis of mature benign cystic teratoma. Neuron specific enolase staining of sections of the tumour was positive, thus confirming the presence of focal collections of primitive neural type cells. Immunohistochemical stains for $\alpha$-fetoprotein, human chorionic gonadotropin, and chromogranin were negative.

The presence of the patient's chronic sinopulmonary complaints, gynaecomastia, small testes, and tall stature suggested the diagnosis of Klinefelter's syndrome which was then confirmed by chromosomal analysis revealing the classic XXY karyotype.

Postoperatively the patient did well. The $\alpha-$ fetoprotein level returned to within the normal range immediately after surgery $(7 \cdot 2 \mathrm{ng} / \mathrm{ml})$ and remains within the normal range at one year follow up. The patient remains asymptomatic and has no evidence of recurrent disease.

\section{Discussion}

The differential diagnosis of an anterior mediastinal mass includes thymic lesions, lymphoma, endocrine tumours, germ cell tumours and, rarely, various other benign tumours such as fibroma or lipoma. In our patient, however, the absence of clinical and radiological features consistent with thymoma or lymphoma, and the elevation of the $\alpha$-fetoprotein level, strongly suggested the diagnosis of a germ cell tumour. Such tumours account for approximately $15 \%$ of all anterior mediastinal masses in adults. ${ }^{1}$

Serum markers are sometimes useful in evaluating a patient with a suspected germ cell tumour. In particular, an elevated $\alpha$-fetoprotein level strongly suggests the diagnosis of a non-seminomatous germ cell tumour. In our patient, however, while the elevated $\alpha$-fetoprotein level suggested a malignant germ cell tumour, careful scrutiny of multiple sections through the mass revealed no evidence of malignant transformation.

Treatment for mediastinal germ cell tumours includes chemotherapy for malignant cell types followed, in some cases, by surgical 


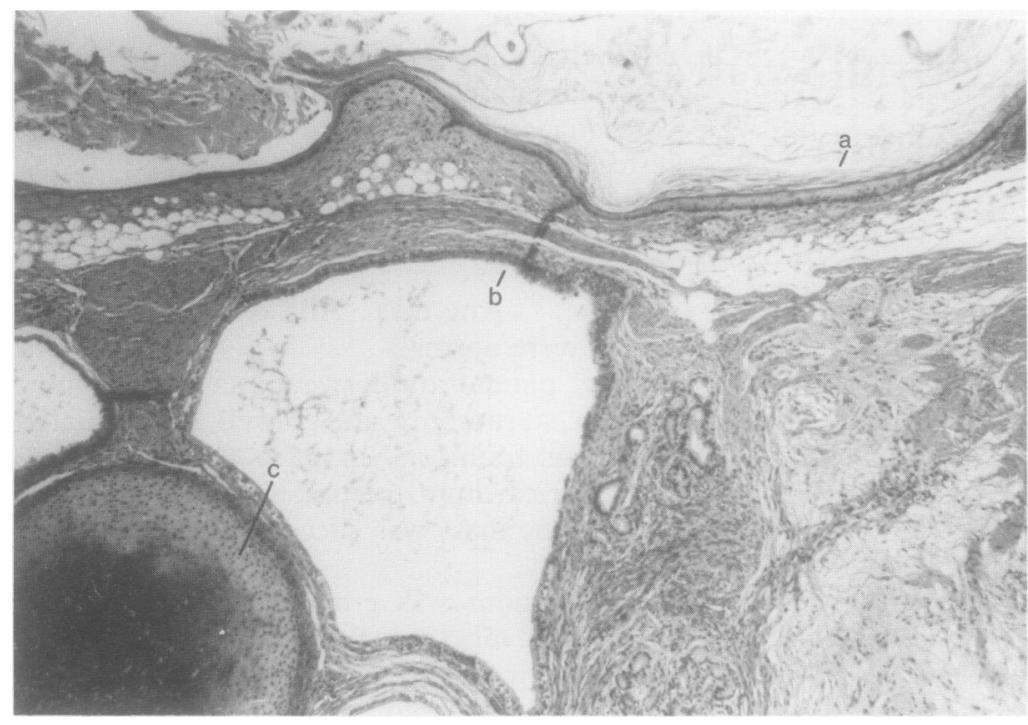

Figure 2 Photomicrograph of the tumour showing the three basic tissue elements: $a$, ectoderm (epidermis); $b$, endoderm (respiratory epithelium); and $c$, mesoderm (cartilage). Original magnification $\times 80$, reduced to $63 \%$ during origination.

removal of residual tumour. Sometimes even benign tumours may need to be removed to avoid erosion into vital structures (pericardium, aorta, and oesophagus) and life threatening complications.

Including this patient, only 23 cases have reported a mediastinal germ cell tumour occurring in association with Klinefelter's syndrome. ${ }^{23}$ Of these, 10 were classified as teratocarcinomas, three choriocarcinomas, three embryonal cell carcinomas, three teratomas, two mixed cell tumours, one seminoma, and one remained unclassified. The association between Klinefelter's syndrome and mediastinal germ cell tumours appears to be more than coincidental, with $21(7 \cdot 7 \%)$ of 272 men with mediastinal germ cell tumours reviewed retrospectively having underlying Klinefelter's syndrome. ${ }^{2}$ Considering that the incidence of Klinefelter's syndrome overall appears to be $0 \cdot 2 \%,{ }^{2}$ the chance of a man with an anterior mediastinal mass having Klinefelter's syndrome is approximately 40 times greater than in the general population.

While reasons for the association between Klinefelter's syndrome and mediastinal germ cell tumours remain speculative, some have proposed an aberration occurring during embryogenesis as the potential mechanism. ${ }^{4}$ During embryogenesis cells of the germinal epithelium, which arise from the embryonic disc apart from the urogenital ridge, migrate through the mediastinum towards the developing gonads. If this migratory process is disrupted, a group of these cells may be abnormally found in the mediastinum. However, other factors such as an abnormal hormonal milieu may also contribute to the failed embryonic cell migration.

In summary, as this case illustrates, patients with Klinefelter's syndrome appear to be at an increased risk for the development of a mediastinal mass of germ cell origin. Chest physicians in particular should be aware of this association.

The authors express appreciation to $\mathrm{Dr}$ Si-Chun Ming for performing the histological examination of this case.

1 Mullen B, Richardson JD. Primary anterior mediastinal tumors in children and adults. Ann Thorac Surg 1986;42:338-45.

2 Lachman MF, Kim F, Koo BC. Mediastinal teratoma associated with Klinefelter's syndrome. Arch Pathol Lab Med 1986;110:1067-71.

3 Nielsen HL, Frandsen F. Klinefelter's syndrome associated with primary mediastinal germinal cell tumor. Ugeskr Laeger 1989;151:2897-8.

4 Curry WA, McKay CE, Richardson RL, Greco FA. Klinefelter's syndrome and mediastinal germ cell neoplasms. $\mathcal{f}$ Urol 1981;125:127-9.
Thorax 1994;49:284-286

Department of

Diagnostic Imaging

N J O'Hare

P J Freyne

Department of

Cardiothoracic

Surgery

D A Luke

Department of

Respiratory Medicine

L J Clancy

J S Prichard

St James' Hospital,

Dublin

Department of

Oncology, Mater

Misericordiae

Hospital, Dublin,

Ireland

K J O'Byrne

D N Carney

Reprint requests to:

Dr K J O'Byrne, ICRF

Clinical Oncology Unit,

Churchill Hospital,

Headington, Oxford

OX3 $7 \mathrm{LJ}$.

Received 7 December 1992

Returned to authors

2 February 1993

Revised version received

7 June 1993

Accepted for publication

9 June 1993

\section{Imaging of bronchial carcinoid tumours with indium-111 pentetreotide}

\author{
K J O'Byrne, $\mathrm{N}$ J O'Hare, P J Freyne, \\ D A Luke, L J Clancy, J S Prichard, \\ D N Carney
}

\begin{abstract}
Neuroendocrine tumours are characterised by the expression of high affinity binding sites for somatostatin. The detection of bronchial carcinoid tumours through scintigraphic imaging is described in two patients using the novel radiolabelled somatostatin analogue indium-111 pentetreotide.
\end{abstract}

(Thorax 1994;49:284-286)
Large numbers of high affinity somatostatin binding sites have been found on most tumours characterised by the expression of neuroendocrine markers. ${ }^{1}$ The development of radiolabelled somatostatin analogues for radiodiagnostic purposes has led to the detection of such tumours in vivo through scintigraphic imaging. ${ }^{2-6}$ In a recent study Lamberts et al detected the primary tumours or metastases in 12 of 13 patients with gastrointestinal carcinoid tumours. ${ }^{2}$ Bronchial carcinoid tumours are well differentiated neuroendocrine malignancies which account for approximately $5 \%$ of all lung tumours. We have investigated the efficacy of the radiolabelled somatostatin analogue indium-111 pentetreotide ${ }^{6}$ in detecting disease in two patients with biopsy proven bronchial carcinoid tumours before surgery.

\section{Methods}

Indium-111 diethylenetriaminopentaacetic acid linked SMS 201995 (octreotide), indium111 pentetreotide, was supplied by Mallinck- 